\title{
Xyridaceae endémicas del Perú
}

\section{Blanca León ${ }^{1,2}$}

${ }^{1}$ Museo de Historia Natural, Av. Arenales 1256, Aptdo. 14-0434, Lima 14, Perú

2 Plant Resources Center, University of Texas at Austin, Austin TX 78712 EE.UU.

blanca.leon@mail.utexas.edu

\section{Resumen}

La familia Xyridaceae es reconocida en el Perú por presentar un género, Xyris, y once especies (Brako \& Zarucchi, 1993; Ulloa Ulloa et al., 2004), todas hierbas. En este trabajo reconocemos un endemismo. Este taxón ha sido encontrado en los pajonales de la región Páramo, a $3300 \mathrm{~m}$ de altitud. No se encuentra representada dentro de áreas naturales protegidas.

Palabras claves: Xyridaceae, Perú, endemismo, plantas endémicas.

\section{Abstract}

The Xyridaceae family in Peru are represented by 11 species in the genus Xyris (Brako \& Zarucchi, 1993; Ulloa Ulloa et al., 2004), all herbs. Here we recognize one endemic taxon. This endemic taxon is found in grasslands of the Paramo region, at $3300 \mathrm{~m}$ elevation. It has not yet been reported from one of Peru's protected areas.

Keywords: Xyridaceae, Peru, endemism, endemic plants.

\section{Xyris tristis L.B. Sm. \& Downs}

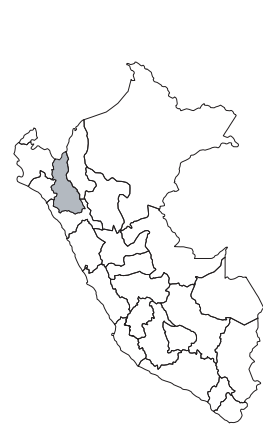

\section{EN, B1a}

Publicación: Publ. Mus. Hist. Nat. «Javier Prado», Ser. B, Bot. 15: 9-10. 1963.

Colección tipo: H.E. Stork \& O.B. Horton

10168

Herbarios: F, US.

Nombre común: Desconocido.

Registro departamental: CA.

Regiones Ecológicas: PAR; 2400—3300

$\mathrm{m}$.

SINANPE: Sin registro.

Herbarios peruanos: Ninguno.

Observaciones: Hierba acaule, conocida de unas pocas poblaciones (Hensold, 1999), en las cuencas tributarias del Marañón. Fue descrita de una planta recolectada en 1938. Amenazas a sus poblaciones, podría estar asociada a los incendios intencionales. 